\title{
Camel Bites: A Case Study with a Summary of Current Epidemiology, Injury Patterns, and Treatment Modalities
}

\author{
Vincent J. Calleo, MD; Patrick O. Curtin, BS; Amy S. Biondich, MD \\ From SUNY Upstate Medical University, Syracuse, NY.
}

\begin{abstract}
Animal bites are a major source of morbidity and mortality worldwide. In the United States, the majority of animal bites come from domestic pets, including dogs, cats, and rodents. Camel bites, on the other hand, are exceedingly rare in the United States and are poorly described in the western medical literature. Special considerations must be made when camel bite injuries occur, as they may be therapeutically challenging. Although some clinical features of camel bites resemble those of the more common animal bite injuries, the camel's unique dentition and bite force must be taken into account when managing these wounds.
\end{abstract}

Keywords: exotic animals injuries, bacteriology

\section{Case}

The patient was a 17-year-old male who was transferred from another hospital's emergency department shortly after sustaining a camel bite to his left forearm. The patient had begun working at an exotic animal farm, where his duties included direct animal care, approximately $2 \mathrm{~d}$ before presentation. A camel bit the patient on the left forearm while he was attempting to remove its harness. He denied being lifted off the ground, thrown, or shaken when the camel bit him. He denied any other injuries from the event. He was initially taken to another facility by family members, where he was given levofloxacin $750 \mathrm{mg}$ intravenously. Radiographs of the left forearm did not reveal any fractures or radiopaque foreign bodies. He was transferred to the regional level I trauma center for further evaluation.

Inspection of the wound revealed an approximately 12 $\mathrm{cm}$ laceration on the proximal volar aspect of the left forearm and a $6 \mathrm{~cm}$ laceration of the proximal dorsal aspect of the left forearm (Figure 1). Examination of the wound sites revealed macerated muscle that extended to the bone and extensive surrounding erythema. The patient had +2 radial pulses bilaterally. His upper extremity strength was $5 / 5$ and sensation was normal.

Corresponding author: Vincent J. Calleo, SUNY Upstate Medical University, 34 O'Day Drive, Endicott, NY 13760; e-mail: vcalleo1@ gmail.com.

Submitted for publication July 2017.

Accepted for publication February 2018.
He had difficulty with proximal interphalangeal flexion but was otherwise able to flex, extend, supinate, and pronate the affected extremity. Orthopedic consultation determined that exploration, debridement, and closure in the operating room were indicated.

The patient was taken to the operating room and given cephalexin and piperacillin-tazobactam intravenously. Upon inspection of the volar aspect of the wound, $100 \%$ laceration of the pronator teres and the flexor digitorum superficialis was found. There was also a plane of laceration between the muscle bellies of the extensor digitorum communis and the extensor carpi radialis brevis. Necrotic tissue was removed, and the wound was brought into apposition. A Hemovac drain was secured on the volar aspect of the wound, and a volar sugar-tong splint with extensor extension was placed.

The patient was observed as an inpatient for $24 \mathrm{~h}$. His Hemovac was removed, and he was discharged to home on ciprofloxacin $500 \mathrm{mg}$ twice daily and cephalexin 500 mg 4 times a day. At this time, the patient's physical examination was unchanged. He was given a $0.9 \mathrm{~kg}(2$ lb) weight restriction and was instructed to follow up in 2 wk. On follow-up, the left forearm was healing well (Figures 2 and 3). The patient had normal flexion and extension of the affected extremity as well as good opposition of the thumb. On phone follow-up approximately 2 mo after the surgery, the patient was doing well, had returned to baseline functioning, and was playing tennis without difficulty. 


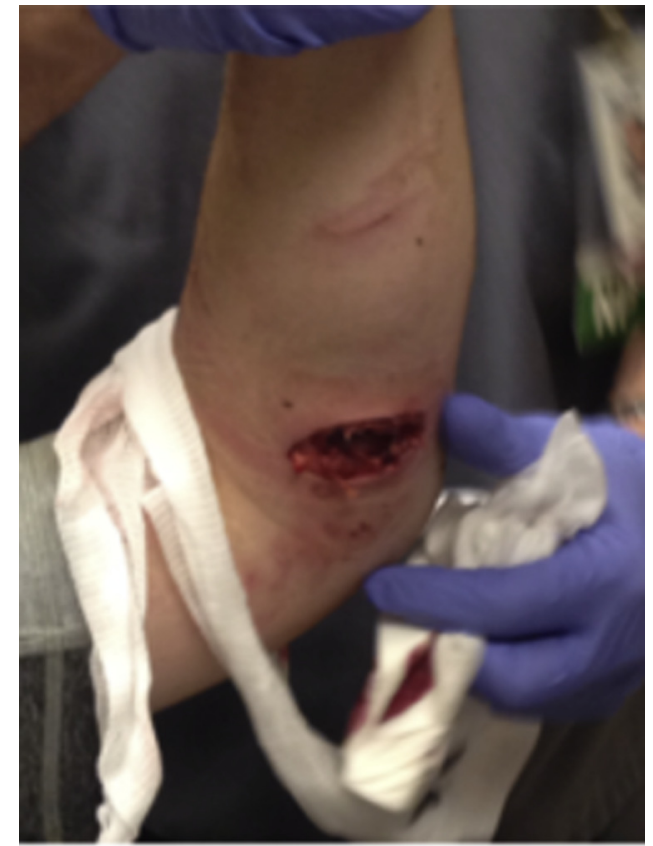

Figure 1. Initial camel bite to the volar aspect of the left forearm.

\section{Discussion}

\section{EPIDEMIOLOGY}

Animal bites are a common cause of injury in the United States. According to the Centers for Disease Control and Prevention, bite injuries from dogs alone account for approximately 4.5 million injuries per year. Camel bites

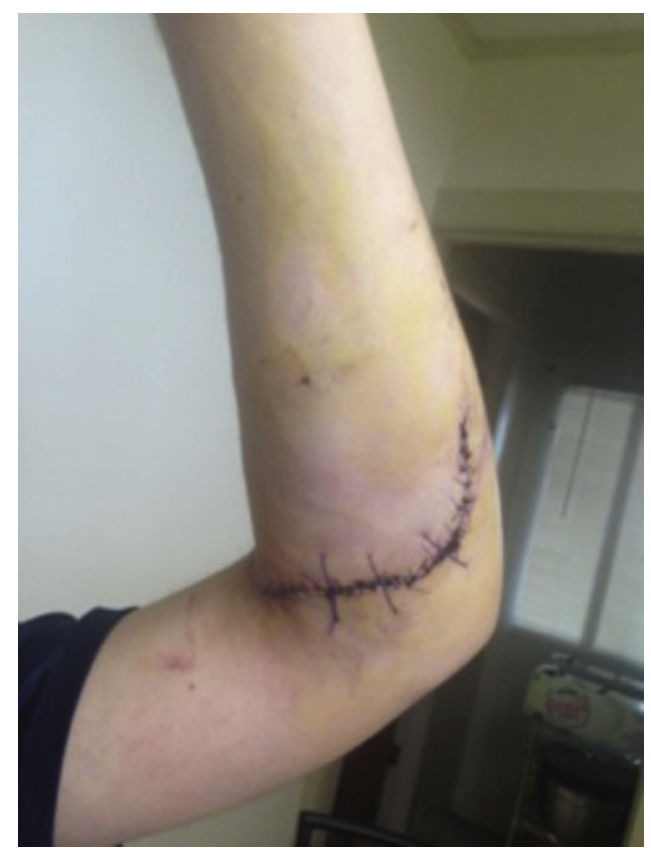

Figure 2. Volar forearm laceration 1-week status postrepair.

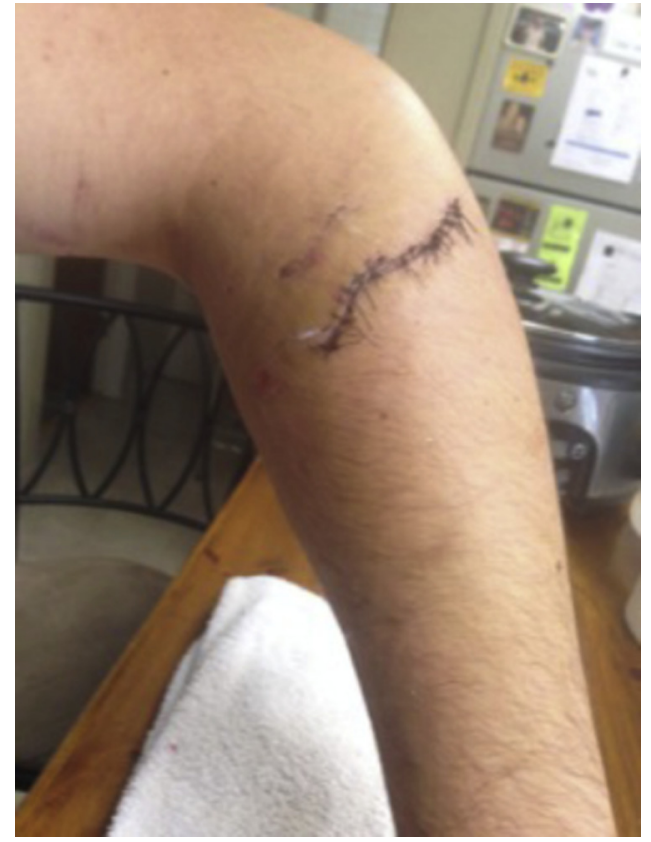

Figure 3. Dorsal forearm laceration 1-week status postrepair.

are relatively rare, particularly in the western world, and little has been written about them in the western medical literature. ${ }^{1,2}$ Although camels are not endemic to the western world, bites can still occur in select locations, such as zoos and exotic animal farms. ${ }^{3}$ Camel bites are most likely to occur during mating season. ${ }^{2,4,5}$ Camels are more likely to bite handlers with a prior offense ${ }^{4}$ (ie, those who had received a prior camel bite) or those who do not have prior experience with camel handling. ${ }^{5}$ In this case, the patient was a new employee at an exotic animal farm and had no prior experience handling camels; this increased his likelihood of being bitten.

\section{INJURY PATTERN AND INFECTION RISK}

Camel bites have the potential to be therapeutically challenging because they may result in both crush and incisional injuries. ${ }^{4,5}$ Mature camels have 34 total teeth. These include 8 incisors, 4 canines, and 22 molars. Due to their large tooth size and strong jaw musculature, camels may generate a bite force of $28 \mathrm{~kg} \cdot \mathrm{cm}^{-2}$ and cause extensive soft tissue, blood vessel, and nerve injuries. ${ }^{3}$ After a camel bites, it may lift, shake, and throw the patient $^{3,6}$; this can significantly worsen the initial penetrating trauma and cause additional injuries.

The majority of camel bites occur on the upper extremities. ${ }^{6,7}$ Wounds can vary greatly, with more serious lacerations penetrating deeply into the soft tissue. Furthermore, bone fractures, as well as dislocations, also can occur. Camel bites can result in both blunt and penetrating injuries. ${ }^{5}$ 
As with most animal bites, camel bites are prone to infection. In addition to Staphylococcus sp, camel bite infections can be polymicrobial; common pathogens include Aeromonas, Pasteurella aerogenes, and Actinobacillus. $^{7}$ Infection rates from camel bites have been reported to be as high as $86 \%{ }^{3}$ Several cases of severe osteolysis from late bone complications (such as osteomyelitis) have been reported. ${ }^{2}$ Patients who sustain camel bites are also at risk for tetanus and rabies if both camel and handler have not been properly vaccinated. ${ }^{3,7}$

\section{TREATMENT}

Upon initial presentation, a patient who has sustained a camel bite should be properly stabilized and thoroughly examined. Once the patient is hemodynamically stable, wound exploration should be done to look for damage to deeper structures. ${ }^{2}$ Imaging studies of the affected area should be performed to evaluate for underlying fractures or dislocations. A complete neurologic examination should be done to assess for any deficits. Any evidence of damage to vascular structures may prompt further imaging studies.

Camel bites should irrigated extensively and debrided well to reduce infection risk. ${ }^{4,7}$ Surgical debridement in the operating room may be necessary in many cases. Although evidence for prophylactic antibiotic use is scant, antibiotics have been given in several case reports, ${ }^{2,4}$ and antibiotic administration is commonly practiced. As with most animal bites, empiric wound cultures are not recommended unless there is evidence of infection. ${ }^{4,7}$ Tetanus prophylaxis should be administered as needed. ${ }^{7}$ Camels can carry rabies, ${ }^{8}$ so this must always be considered, particularly if the camel is not available for direct monitoring.

In summary, camel bites, although rare, can have severe consequences, including penetrating and crush injuries to bony and neurovascular structures. Bites are most commonly seen during camel rutting season or when the handler does not have adequate experience handling camels. Camel bites can have severe complications if not adequately treated. Treatment should include proper vigorous debridement, and antibiotics should be strongly considered.

Author Contributions: Drafting the manuscript (VC, PC); revision of manuscript (VC, PC, AB); approval of final manuscript (VC, PC, AB). Financial/Material Support: None Disclosures: None

\section{References}

1. Nawaz A, Matta H, Hamchou M, Jacobsz A, Al Salem AH. Camel-related injuries in the pediatric age group. $J$ Pediatr Surg. 2005;40(8):1248-51.

2. al-Boukai AA, Hawass NE, Patel PJ, Kolawole TM. Camel bites: report of severe osteolysis as late bone complications. Postgrad Med J. 1989;65(770):900-4.

3. Suess O, Magerkurth O, Da Silva C, Brock M, Pietilä TA. Camel bite: an unusual type of head injury in an infant. J Pediatr Surg. 2004;39(10):e11-3.

4. Ogunbodede EO, Arotiba JT. Camel bite injuries of the orofacial region: report of a case. J Oral Maxillofac Surg. 1997;55(10):1174-6.

5. Abu-Zidan FM, Eid HO, Hefny AF, Bashir MO, Branicki F. Camel bite injuries in united Arab Emirates: a 6 year prospective study. Injury. 2012;43(9):1617-20.

6. Lazarus HM, Price RS, Sorensen J. Dangers of large exotic pets from foreign lands. J Trauma Acute Care Surg. 2001;51(5):1014-5.

7. Dendle C, Looke D. Review article: animal bites: an update for management with a focus on infections. Emerg Med Australas. 2008;20(6):458-67.

8. Abbas B, Omer O. Review of infectious diseases of the camel. Vet Bull. 2005;75(8):1N-16N. 